\title{
Adding a Dietitian to a Danish Liaison-Team after discharge of geriatric patients at nutritional risk may save health care costs
}

Anne Pohju ${ }^{1 *}$, Kerstin Belqaid ${ }^{2}$, Christopher Brandt ${ }^{3}$, Kerstin Lugnet ${ }^{4}$, Anni Linnet Nielsen ${ }^{5}$, Henrik Højgaard Rasmussen ${ }^{6}$, Nanna ML Rasmussen $^{7}$ and Anne Marie Beck ${ }^{8}$

${ }^{1}$ Clinical Nutrition Unit, Helsinki University Central Hospital, Helsinki, Finland

${ }^{2}$ Department of Learning, Informatics, Management and Ethics, Karolinska Institute, Stockholm, Sweden

${ }^{3}$ Department of Medical Gastroenterology, Rigshospitalet, Copenhagen, Denmark

${ }^{4}$ Department of Public Health and Caring Sciences, Uppsala University, Uppsala, Sweden

${ }^{5}$ Department of Oncology, Herlev University Hospital, Herlev, Denmark

${ }^{6}$ Centre for Nutrition and Bowel Disease, Aalborg University Hospital, Aalborg, Denmark

${ }^{7}$ Department of Clinical Nutrition, Regional Hospital West Jutland, Holstebro, Denmark

${ }^{8}$ Department of Nutrition and Health, Metropolitan University College, Denmark

\begin{abstract}
Background: A previous study investigated the value of adding a dietitian to a geriatric discharge Liaison-Team. The scope of this study was to explore the possible economic savings of this.

Methods: Patients, $70+$ and at nutritional risk, were randomized to receive discharge Liaison-Team either with (intervention group, IG) or without a dietitian (control group, CG). The IG received three home visits by the dietitian during a 12-week period. Data included in the economic analysis was time spent by the dietitian, use of oral nutritional supplements (ONS) and number of hospitalization days.

Results: Of the 71 included patients, 34 were in the IG, 30 patients received all three dietitian visits. Cumulated number of hospitalization days was 172 in the IG and 415 in the CG. Use of ONS was $48 \%$ in the IG and $17 \%$ in the CG $(P=0.001)$. Estimated cost for the dietitian and ONS combined in the IG was $€ 9,416$ compared to $€ 1,150$ (ONS only) in the CG. For hospitalizations, estimated cost was $€ 92,020$ in the IG and $€ 220,025$ in the CG. Cost savings added up to $€ 3,048$ per patient in the IG.
\end{abstract}

Conclusion: Adding a dietitian to a Danish geriatric discharge Liaison-Team decreased health care costs

Keywords: Malnutrition; Dietitian; Hospitalization; Length of stay; Cost analysis

\section{Introduction}

Malnutrition is common in older people admitted to hospitals. During hospitalizations, nutritional status often deteriorates further, resulting in a high number of older patients still either malnourished or at nutritional risk at discharge, which imposes an increased risk of re- $/$ hospitalization $[1,2]$.

Hospital stays are generally getting shorter, leaving limited time to improve a poor nutritional status. Even a short hospital stay increases the risk of loss of muscle strength, functional capacity and ability to cope with activities of daily living (ADL) [3].

For older medical patients, Boyd [4] reported only one in three having regained their habitual physical function one year after discharge. Furthermore, many older people continue to lose weight during the first six months after discharge [5]. Hence, it seems necessary to integrate nutritional support not only during hospitalization, but also after discharge. As poor nutritional status is associated with increased use of health care services, this could also have positive effects from an economical point of view [6,7].

A Dutch study reported that the use of oral nutritional supplements (ONS) in the community may lead to cost savings when used for treatment of disease-related malnutrition among old people [8]. The cost savings arise from a reduction in re-/hospitalization, a key driver of costs and also one of the consequences of disease-related malnutrition. Freijer based their economic modelling on a meta-analysis of three studies on nutritional support by means of ONS in old patients and estimated that the probability for re-/hospitalization was reduced by $25 \%$ [8]. The impact of ONS on the reduction of risk for re-/ hospitalization was confirmed in another meta-analysis involving the same three studies plus three additional studies, although this analysis did not consider the cost savings [2].

The cost-saving benefit of ONS was confirmed in a systematic review, assessing the economic value of ONS in the management of disease-related malnutrition among patients of all age groups [9]. Another comprehensive review suggested a cost saving benefit and cost effectiveness of using ONS in the community setting with or without additional use during hospital admissions and regardless of nutritional status or age of the study population [10]. The review focused primarily on studies using ONS, but acknowledged some interventions used also other means of nutritional care, such as dietary counselling. In real life, in addition to ONS, patients can be provided with professional advice including follow-up e.g. by a dietitian which should be taken in consideration in cost analyses. Additionally, length of stay is often not included in cost calculations, even though this gives more accurate information on total expenses in comparison with the hospitalization rate.

*Corresponding author: Anne Pohju, Clinical Nutrition Unit, Meilahti Tower Hospital P.O. Box 340, Finland, Tel: +358 50428 3013; E-mail: anne.pohju@hus.fi

Received August 03, 2016; Accepted August 30, 2016; Published September 06, 2016

Citation: Pohju A, Belqaid K, Brandt C, Lugnet K, Nielsen AL, et al. (2016) Adding a Dietitian to a Danish Liaison-Team after discharge of geriatric patients at nutritional risk may save health care costs. Aging Sci 4: 159. doi: 10.4172/23298847.1000159

Copyright: ( 2016 Pohju A, et al. This is an open-access article distributed under the terms of the Creative Commons Attribution License, which permits unrestricted use, distribution, and reproduction in any medium, provided the original author and source are credited. 
Citation: Pohju A, Belqaid K, Brandt C, Lugnet K, Nielsen AL, et al. (2016) Adding a Dietitian to a Danish Liaison-Team after discharge of geriatric patients at nutritional risk may save health care costs. Aging Sci 4: 159. doi: 10.4172/2329-8847.1000159

The purpose of this study was to investigate both these aspects using data from a formerly published Danish study, which reported a reduction in hospital admissions by adding a dietitian to a discharge Liaison-Team after discharge of geriatric patients [11], from now on referred to as "the original study".

\section{Materials and Methods}

Details of the materials and methods can be found in the original study by Beck [11] and are shortly presented below.

The original study was designed as a twelve-week RCT, comparing a standard discharge Liaison-Team versus a discharge Liaison-Team cooperating with a dietitian. For patients randomized to the intervention group the dietitian joined the discharge Liaison-Team when the patient was discharged from Herlev University hospital.

Before discharge, the dietitian initiated prescription of ONS, if relevant. During the home visit, the dietitian made an individual nutritional assessment focusing on dietary intake, activity level and weight of each participant, as a basis for developing an individual nutrition care plan consistent with estimated nutritional requirements and nutritional rehabilitation goals. Specific focus was on optimizing the intake of protein and the distribution of protein during the day. The information gathered by the discharge Liaison-Team i.e. regarding medical treatment, patient's functional abilities and ability to cope with ADL, as well as need for change in social services was taken into consideration. Overall, three home visits by dietitian were planned. The first visit was to take place at the day of discharge together with the discharge Liaison-Team, while the remaining visits took place approximately three and eight weeks after discharge and were performed by the dietitian alone.

The following characteristics were collected at baseline: age, gender, diagnoses, Nutritional Risk Score (assessed using NRS-2002 screening tool), Cumulated Ambulation Score, The Mini Mental State Examination (MMSE) and use of oral vitamin D supplement.

The following outcome data were collected:

- Energy and protein intake assessed by means of a 4-day dietary record including ONS.

- Hand-grip strength (in kg) measured with a Jamar 5030J1 Hydraulic Hand Dynamometer.

- Leg muscle strength assessed by means of 30-seconds chair stand.

- Mobility assessed using the validated de Morton Mobility Index.

- $\mathrm{ADL}$ assessed using the Barthel-Index-100.

- Quality of Life assessed by means of EuroQol-5D-3L.

- Use of social services, i.e. meals-on-wheels, home nursing care, private care, and rehabilitation plans, gathered by interviewing the participants or their relatives.

- Hospitalizations were evaluated 30 days, 12 weeks and six months after discharge.

- Data on hospital admissions during and after the study was collected from the Hospital Patient Register and the Electronic Patient Record. Information about the number of days spent in hospital during admissions could also be gathered from these.
- Data on mortality 12 weeks and six months after discharge was collected from the Hospital Patient Register and the Electronic Patient Record, together with information obtained from relatives during the intervention period.

\section{Calculation of Costs}

A number of estimations were used as follows:

\section{Costs for Nutritional Support}

Dietitian: The cost for the dietitian was estimated to $€ 31.5 /$ hour based on a monthly salary of $€ 4670$ (information from www.kost.dk, about average salaries for Danish dietitians, retrieved November 2015). Time spent by the dietitian was estimated to an average of six hours per patient. This amount was based on the original study [11] and another Danish study also investigating nutritional support by dietitians after discharge [12].

ONS: The average total cost for one ONS in Denmark is around $€ 2.5$ (2015 prizes, including the reimbursement of 60\%). Available information from the dietary records concerned whether patients used ONS or not, but the exact amount consumed each day during the intervention was not known. Therefore, based on the results of the dietary record performed at the end of the intervention, the amount of ONS consumed was estimated to be averagely one portion per day (at a cost of $€ 2.5$ ) during the three-month intervention.

Health Care Costs: Information on number of days spent in hospital during hospitalizations could be retrieved from the Hospital Patient Register and the Electronic Patient Record. As information on the procedures undertaken during the hospital stay was missing, we estimated the cost for a day in hospital as for an uncomplicated condition, such as when patients are admitted to hospital in need of care for dehydration. The bed/day cost was estimated at $€ 535$ and based on a mean value for a Danish medical patient without registered procedures, giving a general low activity concerning treatment of the patient according to Diagnosis Related Group (DRG) codes. This system is used to categorize Danish patient in different disease groups for reimbursement (www.sundhedsdatastyrelsen.dk).

\section{Ethics}

The protocol for the original study [11] was sent to the Danish Ethical Board, which concluded that approval was not needed as long as the project was carried out as described. Informed consent was obtained from all participants. They were also informed of their right to withdraw their consent at any time.

\section{Statistical Analysis}

All statistical analyses were performed using IBM SPSS Statistics 19. Data was entered in EXCEL and was subsequently exported into SPSS software for analyses. Primary analyses were undertaken using intention to treat principles, i.e. all participants were included in the analyses, regardless of whether they completed the study or not. MannWhitney U test, odds ratio, Pearson Chi-square or Fisher's Exact test of associations were used as appropriate. Data are presented as median (95\% Confidence Intervals (CI) or percentiles (P25; P75)) or percentage (\%). A P-value $<0.05$ was considered statistically significant.

\section{Results}

Between March and September 2013, a total of 140 patients were invited to participate. The participation rate was $51 \%$, resulting in a final sample of 71 included patients. 34 patients were randomised to the intervention group and 37 to the control group. 
Citation: Pohju A, Belqaid K, Brandt C, Lugnet K, Nielsen AL, et al. (2016) Adding a Dietitian to a Danish Liaison-Team after discharge of geriatric patients at nutritional risk may save health care costs. Aging Sci 4: 159. doi: 10.4172/2329-8847.1000159

The characteristics of the participants are presented in Table 1. A larger proportion of participants in the control group were discharged to day care with exercise compared to the intervention group (7 (19\%) vs. $1(3 \%), \mathrm{P}=0.03)$. Otherwise, there were no differences in the clinical or demographic characteristics between the groups. ONS prescriptions were part of the intervention, and the prevalence of participants with such a prescription at discharge was therefore different between the intervention group and the control group (16 (48\%) vs. $5(14 \%)$, $\mathrm{P}=0.001)$. A total of $63(89 \%)$ participants completed the second data collection.

Of the 31 participants who completed the study, 30 (97\%) received the planned three dietitian visits. One participant was hospitalized for a longer time period during the 12 -week study period, which meant the visits were cancelled, and that rescheduling was not possible.

The intervention had a positive effect on nutritionals status in terms of weight, energy and protein intake, but no differences were found in the functional status, quality of life and use of social services between the two groups, see details in the original study [11]. However, some positive tendencies in favour of the intervention group were observed, i.e. in the prevalence of improvement in ADL (20 (69\%) vs. 15 (52\%), $\mathrm{P}=0.180)$, quality of life (22 (71\%) vs. $17(55 \%), \mathrm{P}=0.189)$ and mortality after 6 months (2 (6\%) vs. $6(16 \%), \mathrm{P}=0.264)$ [11].

Patients in the intervention group more often used ONS and spent more time with the dietitian compared to the control group. In addition, the intervention group had a lower number of days spent in the hospital (Table 2). During the six months preceding study inclusion there was no difference in hospitalization rate between the groups (10 (29\%) vs. $13(35 \%), \mathrm{P}=0.623)[11]$

The cost estimations are presented in Table 3. Estimated cost for nutritional support using dietitian and ONS combined in the intervention group was $€ 9,416$ compared to $€ 1,150$ (ONS only) in the control group. The costs for nutritional support were added to the costs for hospitalization days in both groups and then the difference between the groups was calculated. Based on these estimations and assuming that the intervention truly decreased hospitalization days in the intervention group, cost savings would add up to $€ 3,048$ per patient in the intervention group during the six months following discharge from the hospital.

\section{Discussion}

Our results suggest that adding a dietitian to a Danish geriatric Liaison-Team at discharge from hospital could decrease health care costs in terms of reducing both number of hospitalizations and length of stay during hospitalizations among older patients. The observed reduction in hospitalizations is in line with previous reports from systematic reviews $[2,8]$. In contrast to these studies which only included the use of ONS, a review and meta-analysis by Munk et al [13] also investigated the effect of individualised dietary counselling following discharge, including advice on how to optimize energy and

\begin{tabular}{|c|c|c|c|}
\hline Group & $\begin{array}{l}\text { Intervention group }(\mathrm{N}=34) \\
\text { Median }(95 \% \mathrm{Cl})\end{array}$ & $\begin{array}{l}\text { Control group }(\mathrm{N}=37) \\
\text { Median }(95 \% \mathrm{Cl})\end{array}$ & P-value a) \\
\hline $\begin{array}{l}\text { Age, years } \\
\text { Female, N (\%) } \\
\text { Geriatric Medicine department, N (\%) } \\
\text { Discharge Liaison-Team, N (\%) } \\
\text { MMSE, points } \\
\text { Admission diagnosis } \\
\text { - COPD/pneumonia, N (\%) } \\
\text { - Urinary tract infection, N (\%) } \\
\text { - Fall, N (\%) } \\
\text { - Dehydration, N (\%) } \\
\text { - Gastrointestinal disturbances, N (\%) } \\
\text { - Fracture, N (\%) } \\
\text { Nutritional risk score b) } \\
\text { Cumulated Ambulation Score c) } \\
\text { Use of oral vitamin D supplement, N (\%) }\end{array}$ & $\begin{array}{c}85(86 ; 87) \\
22(65) \\
28(82) \\
28(82) \\
27(25 ; 28) \\
3(9) \\
3(9) \\
8(24) \\
3(9) \\
11(31) \\
6(18) \\
3(3 ; 3) \\
5(4 ; 6) \\
15(45)\end{array}$ & $\begin{array}{c}85(82 ; 88) \\
26(70) \\
28(70) \\
27(73) \\
26(24 ; 27) \\
3(8) \\
1(3) \\
10(27) \\
6(16) \\
8(22) \\
9(24) \\
3(3 ; 3) \\
5(4 ; 5) \\
17(46)\end{array}$ & $\begin{array}{l}0.734 \\
0.617 \\
0.491 \\
0.345 \\
0.062 \\
0.673\end{array}$ \\
\hline $\begin{array}{l}\text { Nutritional status } \\
\text { - Weight, kg } \\
\text { - BMl } \\
\text { - Energy intake, MJ/d } \\
\text { - Protein intake, g/d }\end{array}$ & $\begin{array}{c}65.5(56.8 ; 70.8) \\
22.1(20.4 ; 25.6) \\
6.0(5.0 ; 7.1) \\
48(44 ; 60)\end{array}$ & $\begin{array}{c}59.3(55.8 ; 66.0) \\
22.3(20.2 ; 24.0) \\
5.5(5.2 ; 6.1) \\
44(37 ; 49)\end{array}$ & $\begin{array}{l}0.290 \\
0.630 \\
0.122 \\
0.085\end{array}$ \\
\hline $\begin{array}{l}\text { Muscle strength } \\
\text { - Hand grip strength, max kg } \\
\text { Functional status }\end{array}$ & $20.4(16.5 ; 21.2)$ & $18.7(15.9 ; 22.3)$ & 0.739 \\
\hline $\begin{array}{l}\text { - Mobility, score d) } \\
\text { - ADL, score e) } \\
\text { Quality of life, score f) } \\
\text { Social Services }\end{array}$ & $\begin{array}{c}48(41 ; 57) \\
80(70 ; 90) \\
0.623(0.496 ; 0.723)\end{array}$ & $\begin{array}{c}48(41 ; 53) \\
80(70 ; 91) \\
0.708(0.654 ; 0.743)\end{array}$ & $\begin{array}{l}0.974 \\
0.837 \\
0.087\end{array}$ \\
\hline $\begin{array}{l}\text { - Home-care, N (\%) } \\
\text { - Community nursing, N (\%) } \\
\text { - Day care with exercise, N (\%) } \\
\text { - Dare care without exercise, N (\%) } \\
\text { - Meals-on-wheels, N (\%) } \\
\text { ONS prescription, N (\%) }\end{array}$ & $\begin{array}{c}18(53) \\
6(18) \\
1(3) \\
0(0) \\
6(18) \\
16(48)\end{array}$ & $\begin{array}{l}24(65) \\
7(19) \\
7(19) \\
0(0) \\
7(19) \\
5(14)\end{array}$ & $\begin{array}{l}0.307 \\
0.890 \\
0.033 \\
- \\
0.890 \\
0.001\end{array}$ \\
\hline
\end{tabular}

ONS prescription, $\mathrm{N}(\%)$

$6(48)$

(Cl: Confidence Intervals; MMSE: Mini Mental State Examination; ADL: Activities of Daily Living; ONS: Oral Nutritional Supplements)

a) P-values from Pearson Chi-Square or Mann-Whitney U Test

b) NRS-2002 score 0-7 ( $\geq 3$ nutritional risk)

c) Cumulated Ambulation Score $0-6$ (6 is best)

d) de Morton Mobility Index 0-100 (100 is best)

e) Barthel Index 0-100 (100 is best)

f) EQ-5D-3L score 1.000 to -0.624 (1.000 is best)

Table 1: Baseline characteristics of participants $(\mathrm{N}=71)$. 
Citation: Pohju A, Belqaid K, Brandt C, Lugnet K, Nielsen AL, et al. (2016) Adding a Dietitian to a Danish Liaison-Team after discharge of geriatric patients at nutritional risk may save health care costs. Aging Sci 4: 159. doi: 10.4172/2329-8847.1000159

\begin{tabular}{|c|c|c|c|}
\hline Group & $\begin{array}{c}\text { Intervention group } \\
(\mathrm{N}=34)\end{array}$ & $\begin{array}{c}\text { Control group } \\
(\mathrm{N}=37)\end{array}$ & P-value a) \\
\hline ONS use, N (\%) & $13(48)$ & $5(17)$ & $\mathbf{0 . 0 0 1}$ \\
\hline $\begin{array}{c}\text { Time (hours) spent by } \\
\text { dietician }\end{array}$ & 204 & 0 & - \\
\hline Hospitalization rate, N (\%) & $9(28)$ & $16(52)$ & 0.074 \\
\hline $\begin{array}{c}\text { Number of hospitalizations } \\
\text { days, median (P25;P75) }\end{array}$ & $0(0 ; 3)$ & $2(0 ; 20)$ & $\mathbf{0 . 0 1 5}$ \\
\hline $\begin{array}{c}\text { Cumulated number of } \\
\text { hospitalizations days }\end{array}$ & 172 & 415 & - \\
\hline Mortality, N (\%) & $2(6)$ & $6(16)$ & 0.264 \\
\hline
\end{tabular}

a)P-values from Fisher's Exact Test, Pearson Chi-Square or Mann-Whitney U Test. $\left.{ }^{b}\right)$ Dietitian was estimated to have spent $6 \mathrm{~h} /$ patient

Table 2: Information on the intervention, hospitalizations and mortality six months after discharge.

\begin{tabular}{|l|c|c|}
\hline Group & $\begin{array}{c}\text { Intervention } \\
\text { group } \\
(\mathbf{N = 3 4 )}\end{array}$ & $\begin{array}{c}\text { Control } \\
\text { group } \\
\text { (N=37) }\end{array}$ \\
\hline Nutritional support by dieticians at $€ 31.5 /$ hour $^{\text {a) }}$ & $€ 6,426$ & 0 \\
\hline Nutritional support by ONS ${ }^{\text {b) }}$ & $€ 2,990$ & $€ 1,150$ \\
\hline Nutritional support per patient & $€ 277$ & $€ 31$ \\
\hline Hospitalization days six months after dischargec) & $€ 92,020$ & $€ 222,025$ \\
\hline Hospitalization days six months after discharge per patient & $€ 2,706$ & $€ 6,000$ \\
\hline $\begin{array}{l}\text { a) The salary for the dietician was estimated at } € 4,670, \text { which gives an hourly cost } \\
\text { of } € 31.5 . \text { Time spent with patient in the intervention group was } 6 \text { h/person. } \\
\text { b) Estimation per patient using ONS: 92 ONS (1 ONS/day for } 3 \text { months) at a cost } \\
\text { of } € 2.5 \text { per ONS } \\
\text { c) The cost for one day spent in hospital was estimated to } € 535\end{array}$ \\
\hline
\end{tabular}

Table 3: Cost estimations (ONS: Oral Nutritional Supplements).

protein intake by adding snacks or drinks (homemade or ONS). Of the included studies, only one assessed prevalence of hospitalizations and, in contrast to the present study, found no difference in the prevalence six months after discharge. Thus, our results would need to be confirmed in future studies.

Our study has several major strengths. The study [11] was a randomized trial and the compliance with the intervention was high. In addition, the validity of the data regarding hospitalizations is strong due to the use of the Hospital Patient Register and the Electronic Patient Record. As our study considered the costs for both ONS and the dietitians we argue that this better reflects the clinical reality, in contrast to former studies which usually only include the costs for the ONS [8$10]$.

Furthermore, we also included the cumulated numbers of days during hospitalizations and not only the probability of hospitalization.

Finally, we adopted a cautious approach by calculating with a low cost for hospitalizations since we did not adjust for the length of each participant's stay or the actual cause for the hospitalizations. The estimated savings for more complicated patients might therefore have been even larger. It should also be noted that the hospitalization rate before study inclusion did not differ between the groups, which indicates that the patients in the control group were not in a worse condition at study inclusion.

Our results suggested a cost saving of approximately $€ 3,000$ for each patient receiving nutritional support during six months after discharge from hospital. When interpreting these results, it should be kept in mind that this study was not designed as a cost study and we therefore rely heavily on estimated costs as well as some of the variables associated with them, both in terms of quantity (amount of ONS, hours spent by the dietitian) and the actual expenses. In addition, the study took place in a Danish setting, which means that costs and expenses are specific to the Danish health care system. Although the specific cost savings may not be generalizable to other health care settings and countries, the study still provides an example of how improving nutritional care can save health care costs.

A Dutch study by Schilp et al. [14] evaluated the cost-effectiveness of nutritional support to malnourished, community-dwelling old people, provided by a dietitian. Although there are several similarities with our study with regard to demographic characteristics of the included patients and the components of the nutritional intervention, the authors did not find any effect on nutritional status or number of days spent in hospital. However, Schilp and co-workers [14] included a broad selection of services in the cost analysis, which may be one explanation for the discrepancy with the results from our study. Also the study participants in the study by Schilp et al. [14] were communitydwelling people, where our study population was recruited during the hospital stay and therefore might have been frailer and benefit more from the intervention. The prevalence of ONS use and the time spent with the dietitian was greater in our study, which could explain that the intervention used here was more effective in improving nutritional status and thereby reducing hospitalizations.

Beck et al. assessed cost-effectiveness of a multidisciplinary approach including dietitians, providing nutritional support to old people living in nursing homes or receiving home care [15]. In this study, the cost analysis focused on Quality-Adjusted Life Years (QALY), a measure including both the quality and quantity of life lived. Similar to our results, they reported a tendency of a reduction in the number of hospitalizations during the three months intervention period in the intervention group ( $16 \%$ vs. $28 \%, \mathrm{P}=0.323$ ). However, although this information was not used for the QALY analysis, they found a costeffectiveness ratio of DKK 46,000 per QALY.

Dietitians taking part in discharge Liaison-Teams, as in the intervention presented here, is not a standard in the Nordic countries. The original study and our additional results suggest that dietary counselling and systematic follow-up by a dietitian targeted to older patients with nutritional risk after discharge from hospital can decrease hospitalization rate and length of stay. More frequent use of dietitians in the community care of older people might be one of the underutilized factors for a successful transition of older patients from hospital to community care - also from the economical point of view.

To our knowledge, few studies assessing possible cost-savings have focused on the use of dietitians and even fewer on the use of multidisciplinary support. In addition the studies investigating nutritional support often have varying aims and designs, which make them difficult to compare (10). Hence, further research is still needed so that limited health care resources can be targeted in an effective and economically reasonable way.

\section{Conclusion}

This study suggests that adding a dietitian to a geriatric discharge Liaison-Team could decrease health care costs in terms of reducing hospitalizations and days spent in hospital during admissions.

\section{Author Contributions}

$A B$ designed the original study. All authors participated in the analysis of the results included in the present study. $A B$ and $A P$ drafted the manuscript and all other authors critically reviewed and contributed to draft. AP finalized the draft and all other authors read and approved the final manuscript. 
Citation: Pohju A, Belqaid K, Brandt C, Lugnet K, Nielsen AL, et al. (2016) Adding a Dietitian to a Danish Liaison-Team after discharge of geriatric patients at nutritional risk may save health care costs. Aging Sci 4: 159. doi: 10.4172/2329-8847.1000159

\section{Acknowledgement}

This work has been done as a part of the Nordic Nutrition Academy (NNA) in 2014-2016. NNA is an education program for health care professionals with interest in disease-related malnutrition and research. The goal is to increase skills in nutrition issues within health care and research, create networks between experienced and less experienced clinicians/researchers, and integrate clinical work into research. NNA program is based in the Karolinska University Hospital and has been developed in cooperation with several universities in the Nordic region and national societies in clinical nutrition from Denmark (DSKE), Norway (NSKE), Sweden (SWESPEN) together with Baxter and Nestle Health Care Nutrition in the Nordic countries.

The original study has been funded by a grant from the Danish Regions and the Danish Health Cartel.

\section{References}

1. Beck A, Holst M, Rasmussen HH (2013) Oral nutritional support of older (65 years+) medical and surgical patients after discharge from hospital: systematic review and meta-analysis of randomized controlled trials. Clin Rehab 27: 19-27.

2. Stratton RJ, Hébuterne X, Elia M (2013) A systematic review and meta-analysis of the impact of oral nutritional supplements on hospital readmissions. Ageing Res Rev 12: 884-897.

3. Alley DE, Koster A, Mackey D, Cawthon P, Ferrucci L, et al. (2010) Health, Aging and Body Composition Study. Hospitalization and change in body composition and strength in a population-based cohort of older persons. J Am Geriatr Soc 58: 2085-2091.

4. Boyd CM, Landefeld CS, Counsell SR, Palmer RM, Fortinsky RH, et al. (2008) Recovery of activities of daily living in older adults after hospitalization for acute medical illness. J Am Geriatr Soc 56: 2171-2179.

5. Miller MD, Crotty M, Whitehead C, Bannerman E, Daniels LA (2006) Nutritional supplementation and resistance training in nutritionally at risk older adults following lower limb fracture: a randomised trial. Clin Rehab 20: 311-323.
6. Freijer K, Tan SS, Koopmanschap MA, Meijers JM, Halfens RJ, et al. (2013) The economic costs of disease related malnutrition. Clin Nutr 32: 136-141.

7. Freijer K, Lenoir-Wijnkoop I, Russell CA, Koopmanschap MA, Kruizenga HM et al. (2015) The view of European experts regarding health economics for medical nutrition in disease-related malnutrition. Eur J Clin Nutr 69: 539-545.

8. Freijer K, Nuijten MJ, Schols JM (2012) The budget impact of oral nutritiona supplements for disease related malnutrition in elderly in the community setting. Front Pharmacol 3: 78.

9. Freijer K, Bours MJ, Nuijten MJ, Poley MJ, Meijers JM, et al. (2014) The economic value of enteral medical nutrition in the management of diseaserelated malnutrition: a systematic review. J Am Med Dir Assoc 15: 17-29.

10. Elia M, Normand C, Laviano A, Norman K (2016) A systematic review of the cost and cost effectiveness of using standard oral nutritional supplements in community and care home settings. Clin Nutr 35: 125-137.

11. Beck A, Andersen UT, Leedo E, Jensen LL, Martins K, et al. (2015) Does adding a dietician to the Liaison-Team after discharge of geriatric patients improve nutritional outcome: a randomised controlled trial. Clin Rehab 29: 1117-1128.

12. Beck A, Kjær S, Hansen BS, Storm RL, Thal-Jantzen K, et al. (2013) Follow-up home visits with registered dieticians have a positive effect on the functional and nutritional status of geriatric medical patients after discharge. A randomised controlled trial. Clin Rehab 27: 483-493.

13. Munk T, Tolstrup U, Beck A, Holst M, Rasmussen $\mathrm{HH}$, et al. (2016) Individualised dietary counselling for nutritionally at-risk older patients following discharge from acute hospital to home: a systematic review and meta-analysis. J Hum Nutr Diet 29: 196-208.

14. Schilp J, Bosmans JE, Kruizenga HM, Wijnhoven HA, Visser M (2014) Is Dietetic Treatment for Undernutrition in Older Individuals in Primary Care CostEffective? J Am Med Dir Assoc 15: 226.e7-226.e13.

15. Beck A, Keiding H, Christensen AG, Hansen BS, Damsbo-Svendsen S, et al (2015) Multidisciplinary nutritional support for undernutrition in nursing home and home-care is cost-effective. Nutr $\mathrm{J} 13: 86$. 